\title{
Análise da presença de microrganismos patógenos em maquiagens: revisão da
}

\section{literatura}

\author{
Analysis of the presence of pathogenic microorganisms in makeup: literature review \\ Análisis de la presencia de microorganismos patógenos em el maquillaje: revisión de literatura
}

Recebido: 25/11/2021 | Revisado: 30/11/2021 | Aceito: 01/12/2021 | Publicado: 12/12/2021

\author{
Jéssica Soares Silva \\ ORCID: https://orcid.org/0000-0002-5280-7581 \\ Faculdade Independente do Nordeste, Brasil \\ E-mail: jessicasoaressilva03@gmail.com \\ Morrana Porto Santos \\ ORCID: https://orcid.org/0000-0001-8595-2411 \\ Faculdade Independente do Nordeste, Brasil \\ E-mail: morranan72@hotmail.com \\ Tayanne Andrade Dos Santos \\ ORCID: https://orcid.org/0000-0002-7977-6308 \\ Faculdade Independente do Nordeste, Brasil \\ Email: tayanne.as@hotmail.com \\ Tatielle Pereira Silva \\ ORCID: https://orcid.org/0000-0002-8086-0574 \\ Faculdade Independente do Nordeste, Brasil \\ E-mail: tatielle@fainor.com.br
}

\begin{abstract}
Resumo
Este artigo tem como objetivo analisar estudos científicos que avaliaram a presença de microrganismos patogênicos em cosméticos. Desta forma, foi realizada uma revisão de literatura, a partir das bases de dados scielo, google acadêmico, Seminário Transdisciplinar da Saúde, Revista de ciências farmacêuticas básica e aplicada, entre outras fontes de dados, publicados nos idiomas português e inglês. Os cosméticos são preparações compostas por substâncias naturais ou sintéticas que podem ser utilizadas externamente em várias partes do corpo humano, e tem por finalidade limpar, adicionar fragrância, alterar sua aparência ou corrigir o odor corporal. Algumas maquiagens podem causar reações adversas aos usuários. Esses efeitos geralmente podem ser causados por fatores pessoais como fisiológicos ou pelo uso impróprio do produto, portanto, testes biológicos para avaliação de segurança devem ser realizados antes que os cosméticos sejam colocados no mercado. A garantia na qualidade dos cosméticos é um fator de suma importância no que diz respeito à saúde da pele. Vários microrganismos, patógenos ou não, podem estar presentes nas formulações cosméticas, com tudo a presença de outros microrganismos oriundos do uso constante e até indevido destes cosméticos podem levar a um desequilíbrio da microflora da pele cosmética. Conclui-se, a partir dos resultados deste estudo, a presença de bactérias do grupo Staphylococcus em cosméticos, sendo elas subdivididas em: aureus e epidermidis. Tais bactérias podem trazer prejuízos para a saúde humana, que vão desde infecções simples até as mais complexas devido ao fato de que os cosméticos são produtos não estéreis.
\end{abstract}

Palavras-chave: Microrganismos; Cosméticos; Análise; Pele; Revisão.

\begin{abstract}
This article aims to analyze scientific studies that evaluated the presence of pathogenic microorganisms in cosmetics. Thus, a literature review was carried out, based on scielo databases, academic google, Transdisciplinary Health Seminar, Journal of basic and applied pharmaceutical sciences, among other data sources, published in Portuguese and English. Cosmetics are preparations composed of natural or synthetic substances that can be used externally in various parts of the human body, and are intended to clean, add fragrance, change their appearance or correct body odor. Some makeup can cause adverse reactions to users. These effects can usually be caused by personal factors such as physiological or by improper use of the product, therefore, biological tests for safety evaluation must be carried out before the cosmetics are placed on the market. The guarantee in the quality of cosmetics is an extremely important factor with regard to skin health. Several microorganisms, pathogens or not, can be present in cosmetic formulations, but the presence of other microorganisms from the constant and even improper use of these cosmetics can lead to an imbalance of the cosmetic skin microflora. It is concluded, from the results of this study, the presence of bacteria of the Staphylococcus group in cosmetics, which are subdivided into: aureus and epidermidis. Such bacteria can harm human health, ranging from simple to more complex infections due to the fact that cosmetics are non-sterile products. Keywords: Microorganisms; Cosmetics; Analysis; Skin; Review.
\end{abstract}




\begin{abstract}
Resumen
Este artículo tiene como objetivo analizar estudios científicos que evaluaron la presencia de microorganismos patógenos en cosméticos. Así, se realizó una revisión bibliográfica, basada en bases de datos scielo, google académico, Seminario Transdisciplinario de Salud, Revista de ciencias farmacéuticas básicas y aplicadas, entre otras fuentes de datos, publicados en portugués e inglés. Los cosméticos son preparaciones compuestas por sustancias naturales o sintéticas que se pueden usar externamente en diversas partes del cuerpo humano, y están destinadas a limpiar, agregar fragancia, cambiar su apariencia o corregir el olor corporal. Algunos maquillajes pueden provocar reacciones adversas a los usuarios. Estos efectos generalmente pueden ser causados por factores personales como fisiológicos o por un uso inadecuado del producto, por lo que se deben realizar pruebas biológicas para la evaluación de la seguridad antes de la comercialización de los cosméticos. La garantía en la calidad de los cosméticos es un factor de suma importancia para la salud de la piel. Varios microorganismos, patógenos o no, pueden estar presentes en las formulaciones cosméticas, pero la presencia de otros microorganismos por el uso constante e incluso inadecuado de estos cosméticos puede conducir a un desequilibrio de la microflora cosmética de la piel. Se concluye, a partir de los resultados de este estudio, la presencia de bacterias del grupo Staphylococcus en cosmética, las cuales se subdividen en: aureus y epidermidis. Dichas bacterias pueden dañar la salud humana, desde infecciones simples hasta más complejas debido al hecho de que los cosméticos son productos no estériles.
\end{abstract}

Palabras clave: Microorganismos; Productos cosméticos; Análisis; Piel; Revisión.

\title{
1. Introdução
}

A pele é o maior e também um dos órgãos mais importantes do corpo humano, portanto, quando este órgão é lesado por doença ou apenas uma deformidade causada por variáveis externas, todo o corpo também é prejudicado. Embora isso seja indesejável, certas maquiagens podem causar reações adversas aos usuários. Esses efeitos geralmente podem ser causados por fatores pessoais como fatores fisiológicos ou até mesmo pelo uso impróprio do produto. Portanto, testes biológicos para avaliação de segurança devem ser realizados antes que os cosméticos sejam colocados no mercado. A pele compõe-se, essencialmente, de três grandes camadas de tecidos: uma camada superior - a epiderme; uma camada intermediária - a derme; e uma camada profunda - a hipoderme ou tecido celular subcutâneo. Os queratinócitos da camada sintetizam grânulos lamelares, que terão importância na barreira de proteção oferecida pela epiderme (Lucas, 2004).

Os cosméticos são preparações compostas por substâncias naturais ou sintéticas que podem ser utilizadas externamente em várias partes do corpo humano como: pele, sistema capilar, unhas, lábios. Sua única ou principal finalidade é limpar, adicionar fragrância, alterar sua aparência ou corrigir o odor corporal e / ou protegê-los e mantê-los em boas condições (ANVISA, 2005). Segundo Galembeck (s/d online), cosméticos são substâncias, misturas ou formulações usadas para melhorar ou proteger a aparência do corpo humano.

No passado, o principal objetivo dos cosméticos era encobrir defeitos físicos, sujeira e odores. Com as mudanças nos hábitos de limpeza e cuidados pessoais, agora é usado de forma mais ampla e diferente do que era antes. Os produtos cosméticos são usados pelo homem desde os tempos antigos. Inicialmente, as fontes de seus ingredientes eram essencialmente plantas, animais e minerais. No entanto, o avanço da tecnologia resultou na inclusão de muitos produtos químicos sintéticos na formulação desses produtos. Atualmente, o uso, principalmente como produtos de higiene, é bastante difundido e atinge uma parcela cada vez maior da população. As formulações cosméticas são complexas e utilizam muitas matérias-primas diferentes, pois cada cosmético deve ter múltiplas características ao mesmo tempo para se adequar à aplicação desejada (Galembeck; Csoares, 2011).

Os cosméticos no Brasil são controlados pela Câmara Técnica de Comércio de Cosméticos da ANVISA (CATEC / ANVISA) e pela resolução RDCnº. 211, 14 de julho de 2005. De acordo com a Resolução $n^{\circ} 79 / 2000$ e Resolução $n^{\circ}$ 335/1999, os produtos dessa indústria são divididos em 4 categorias: Produtos de higiene; Cosmético; Perfume; Produto para bebês e 2 categorias de risco: Risco de nível 1, risco menor. Por exemplo: maquiagem (pó, base líquida, sombra, rímel, Delineador, batom e pasta líquida, perfume, sabonete, xampu, creme de barbear, Pasta de dente, creme hidratante, gel para pentear, talco, sal de banho, etc. Risco de nível 2, risco potencial. Por exemplo: shampoo anti-caspa, desodorante e sabonete 
líquido Produtos pessoais femininos, desodorante para axilas, talco anti-séptico em pó, protetor solar e labial, creme facial Agente de remoção de cabelo, repelente de mosquitos, tintura de cabelo, spray para pentear e estilista de cabelo, Descolorante de cabelo, enxaguatório bucal, esmalte, óleo de massagem e todos os outros produtos Bebês, embora completamente inofensivos, são classificados como um grupo de risco de nível 2 porque passa por um processo de inspeção mais rigoroso antes de colocá-lo no mercado.

A partir de relatos históricos é possível perceber que a história da maquiagem começou na era pré-histórica, entretanto o seu uso para fins de embelezamento só foi possível ser percebido em cerca de 4000 a.C no Egito. Lopes (2010) refere que os egípcios, tanto homens quanto mulheres, possuíam rotinas de cuidados pessoais de beleza. Eles extraíam os elementos da natureza e os utilizavam para embelezamento, hidratação, purificação e proteção do forte calor.

Segundo Holland e Bojar (2000), a microflora da pele é um componente integrante da pele humana normal e, consequentemente, para compreender a função e as atividades da pele requer uma abordagem holística, que inclui as atividades da microflora da pele. Nesta microflora é possível encontrar bactérias gram-positivas como: Propionibacterium, Corynebacterium, Brevibacterium, Staphylococcus, Dermacoccus, entre outras. Em 1981, em Atlanta, foram avaliadas 1345 amostras de sombras de uso para clientes, de diferentes marcas, sendo 67\% destas, ou seja, a maior parte das sombras possuía contaminação por patógenos do tipo Staphylococcus, Micrococcus, Corynebacterium, Acinetobacter, Bacillus e Moraxella(Dawson; Reinhardt , 1981). A diferença entre bactérias inofensivas e um agente patogênico é devido à capacidade da pele como um todo de resistir a doenças e infecções, não às propriedades embutidas do microrganismo.

Frente ao exposto, este estudo apresenta como objetivo analisar estudos científicos que avaliaram a presença de microrganismos patogênicos em cosméticos.

\section{Metodologia}

Realizou-se uma revisão da literatura, durante o ano de 2021 onde foram utilizados artigos científicos nos idiomas português e inglês, que foram consultados em base de dados Scientific Library online (SciELO), Google, Seminário Transdisciplinar da Saúde, Revista de Ciências Farmacêuticas Básica e Aplicada, bem como documentos e dados publicados pela ANVISA entre outras fontes de dados. O presente trabalho baseou-se no referencial da pesquisa bibliográfica, que consiste no exame da literatura científica para levantamento e análise do que já se produziu sobre determinado tema. Envolveu as atividades básicas de identificação, compilação, fichamento, análise e interpretação (Marconi \& Lakatos, 2008). A pesquisa bibliográfica não é mera repetição do que já foi dito ou escrito sobre certo assunto, mas propicia o exame de um tema sob novo enfoque ou abordagem, chegando a conclusões inovadoras (Marconi \& Lakatos, 2015).

Foram selecionados artigos com a temática voltada para o controle de qualidade e análise de cosméticos entre o período de 2004 a 2020, as buscas foram realizadas no período entre fevereiro de 2021 a setembro de 2021. A busca foi feita utilizando as seguintes descrições: microrganismo patogênicos, cosméticos, controle de qualidade de cosméticos e análise microbiológica de maquiagens. A partir disso os principais aspectos de cada trabalho selecionado foram: objetivos, métodos, resultados e conclusões e assim foi possível organizá-los e resumi-los em tabela. E os critérios de inclusão e exclusão estão descritos no organograma (Quadro 1) a abaixo, seguido pelo fluxograma (Quadro 2) onde consta a quantidade artigos e como foram selecionados. 
Quadro 1. Organograma - critérios de inclusão e exclusão de estudos sobre controle de qualidade de cosméticos.

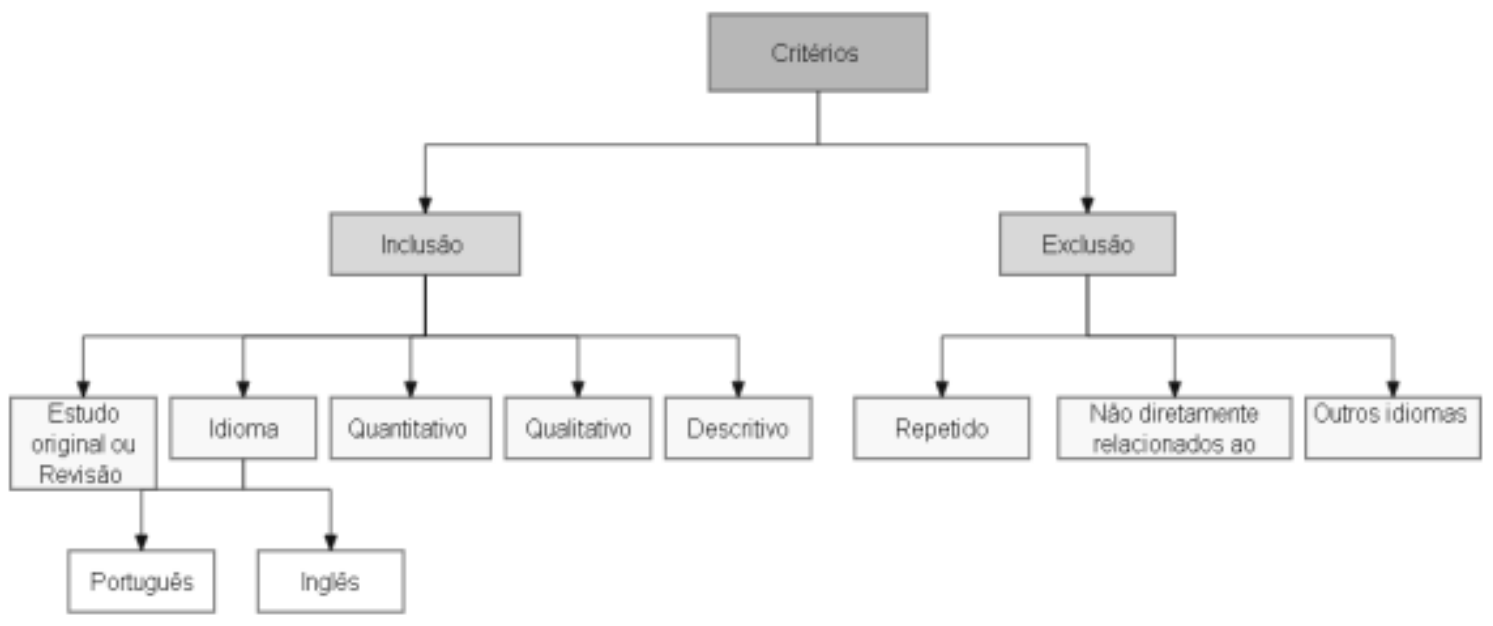

Fonte: Autores, dados da pesquisa (2021).

Quadro 2. Fluxograma- critérios de inclusão e exclusão na forma qualitativa.

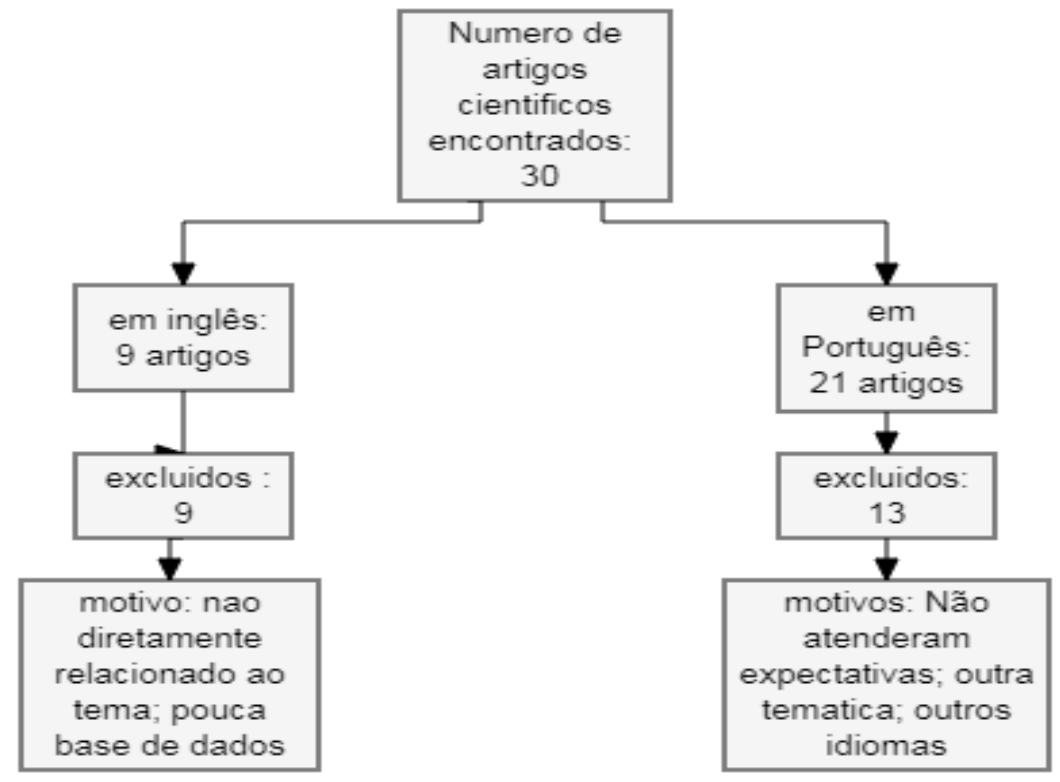

Fonte: Autores, dados da pesquisa (2021).

\section{Resultados}

Ao todo foram encontrados 30 artigos científicos, destes 8 (oito) atenderam aos critérios de inclusão, como é possível observar na Tabela 1. A partir dos mesmos foi possível realizar um comparativo em relação ao controle de qualidade de maquiagens, dentre os estudos escolhidos foram selecionados para os resultados apenas os em português, sendo assim, os trabalhos em inglês não entraram nesse comparativo. 
Tabela 1 - Resumo da informação dos estudos selecionados e identificados nas ferramentas de busca, entre os anos 2015 a 2020 .

\begin{tabular}{|c|c|c|c|c|}
\hline Autor & Título & $\begin{array}{c}\text { Ano de } \\
\text { publicação }\end{array}$ & $\begin{array}{l}\text { Tipos de } \\
\text { Cosméticos }\end{array}$ & Microrganismos encontrados \\
\hline $\begin{array}{lll}\text { ACCACIO, } & \text { L. } & \text { L., } \\
\text { ALMEIDA, } & \text { C. } & \text { R. } \\
\text { BONI, S } & & \end{array}$ & $\begin{array}{l}\text { Presença de staphylococcus aureus e } \\
\text { staphylococcus epidermidis em máscaras } \\
\text { de cílios utilizadas em salões de beleza na } \\
\text { cidade de Sarandi-PR }\end{array}$ & Nov. 2015 & Máscaras de cílios & Staphylococcus epidermidis \\
\hline $\begin{array}{l}\text { BENVENUTTI, A. } \\
\text { de S.; VEIGA, A.; } \\
\text { ROSSA, L. S }\end{array}$ & $\begin{array}{l}\text { Avaliação da qualidade microbiológica de } \\
\text { maquiagens de uso coletivo }\end{array}$ & Dez. 2016 & $\begin{array}{l}\text { Pó facial; Batom; blush } \\
\text { Máscara de cílios; Sombras }\end{array}$ & $\begin{array}{l}\text { Staphylococcus coagulase } \\
\text { positivo, sugestivo de } \\
\text { Staphylococcus Aureus }\end{array}$ \\
\hline $\begin{array}{l}\text { MACEDO, Cynthya } \\
\text { Hellen Costa et al }\end{array}$ & $\begin{array}{l}\text { Análise microbiológica de provadores de } \\
\text { maquiagens }\end{array}$ & 2020 & $\begin{array}{l}\text { Bases líquidas; Sombras em } \\
\text { pó;Batom; Pós faciais; } \\
\text { Máscaras de cílios; Pó para } \\
\text { Sobrancelhas }\end{array}$ & $\begin{array}{l}\text { Klebsiella sp; Kocuria Kristinae; } \\
\text { Aspergillus niger }\end{array}$ \\
\hline $\begin{array}{l}\text { SILVA, J. C. P. A.; } \\
\text { CAMARGO, B. }\end{array}$ & $\begin{array}{l}\text { Contaminação de maquiagens de uso } \\
\text { coletivo por staphylococcus aureus e } \\
\text { staphylococcus epidermidis. }\end{array}$ & 2017 & $\begin{array}{l}\text { Pincel; Esponja; Batom; } \\
\text { Máscara de cílios; Sombra; } \\
\text { Lápis de olho }\end{array}$ & $\begin{array}{l}\text { Staphylococcus aureus; } \\
\text { Staphylococcus epidermidis. }\end{array}$ \\
\hline $\begin{array}{l}\text { SOUZA, N. A.; } \\
\text { SÁBER, M. L. }\end{array}$ & $\begin{array}{l}\text { Análise da presença de staphylococcus sp. } \\
\text { Em creme labial de manteiga de cacau } \\
\text { antes e após o uso. }\end{array}$ & 2018 & Manteiga de cacau & $\begin{array}{l}\text { Staphylococcus aureus; } \\
\text { Staphylococcus epidermidis }\end{array}$ \\
\hline SIMOES, N. R. Q. & $\begin{array}{l}\text { Avaliação da qualidade microbiana de pós } \\
\text { cosméticos }\end{array}$ & 2015 & Pó facial & $\begin{array}{l}\text { Escherichia coli; Staphylococcus } \\
\text { aureus }\end{array}$ \\
\hline RODRIGUES, L. R. & $\begin{array}{l}\text { Análise Microbiológica de Batons de Uso } \\
\text { Compartilhado na Cidade de Juazeiro do } \\
\text { Norte-CE }\end{array}$ & 2020 & Batom & $\begin{array}{l}\text { Staphylococcus aureus; } \\
\text { Escherichia coli; Enterococcus sp; } \\
\text { Pseudomonas aeruginosa }\end{array}$ \\
\hline $\begin{array}{l}\text { VASSOLER, M.; } \\
\text { et.al. }\end{array}$ & $\begin{array}{l}\text { Contaminação microbiológica } \\
\text { provadores de batons disponíveis } \\
\text { consumidores }\end{array}$ & 2020 & Batom & $\begin{array}{l}\text { Staphylococcus coagulase- } \\
\text { negativo; Staphylococcus aureus; } \\
\text { Bacillus sp.; Cladosporium sp.; } \\
\text { Aspergillus sp }\end{array}$ \\
\hline
\end{tabular}

Fonte: Autores, dados da pesquisa (2021).

\section{Discussão}

Segundo os dados coletados na pesquisa, foi possível observar quais são os microrganismos presentes nas amostras de cada estudo e quais foram os testes utilizados para a identificação dos mesmos, destacando também a importância do controle de qualidade nesses produtos. Os cosméticos presentes nos estudos selecionados foram batom, pó facial, manteiga de cacau, bases líquidas, sombras em pó, máscaras de cílios, pó para sobrancelhas, blush, lápis de olho e sombras. Além dos cosméticos também foi selecionado um estudo no qual os produtos analisados foram pincel e esponja pois são utensílios usados em contato direto com os cosméticos e podem apresentar crescimento microbiológico como mostra o estudo realizado.

De acordo com Sartori, Lopes e Garatini (2010), “o termo cosmético é derivado da palavra grega kosmétikos, que teve origem na palavra kosmos, a qual está relacionada com algo organizado, harmonioso e em equilíbrio", aos quais são usados diversos tipos de compostos orgânicos para manter o equilíbrio e melhorar a estética visual.

Os cosméticos são produtos de uso externo do corpo humano com a finalidade de limpeza e embelezamento da área facial, corporal e capilar, podendo ser de origem sintética ou natural. (Garbaccio \& Oliveira, 2018).

Garbaccio e Oliveira (2013) enfatizam que os cosméticos são constituídos por compostos orgânicos, inorgânicos e água, que fornecem condições adequadas para o crescimento e desenvolvimento de microrganismos. Destaca-se que a microflora da pele de qualquer pessoa é única e pode ser transferida para outras usando produtos e acessórios compartilhados, como esponjas e pincéis, que podem ameaçar a saúde dos usuários. 
Os cosméticos podem acarretar fatores de risco biológico, ou seja, na transmissão de doenças de uma pessoa para outra, através do contato direto com o cosmético ou por meio de objetos e utensílios contaminados, os quais são utilizados na aplicação do mesmo (Araújo et al., 2018).

Para impedir a proliferação de microrganismos em cosméticos, como por exemplo, as maquiagens, estes produtos possuem conservantes em sua composição. Além disso, estas substâncias químicas também protegem contra oxidações indesejáveis, assegurando, dessa forma, seu prazo de validade e segurança de uso. (Souza, 2018).

De acordo com Macedo (1998), cada pessoa tem uma pele única, porém, há algumas características gerais, como o fato de que a pele tem sempre a mesma estrutura básica, formada por três camadas: epiderme, derme e hipoderme. Ter uma boa pele é uma questão de saúde, ela faz a ponte entre o corpo e o meio ambiente. Por isso, absorve fatores externos, como a luz ultravioleta e centenas de tóxicos de natureza química e orgânica, evitando que esses agressores atinjam o organismo. Além disso, muitos distúrbios orgânicos podem ser diagnosticados por meio de sinais presentes na pele.

Para Draelos (2005) a pele, além de ser o primeiro órgão de defesa de nosso corpo contra as adversidades do meio externo, possui papéis importantes, cujas complexidades e higidez contribuem para a manutenção da homeostase do organismo. Tais propriedades, no entanto, só são desempenhadas com excelência se o tecido tegumentar estiver em condições normais e plenas de funcionamento e cuidado.

Ribeiro (2010) informa que a pele humana quando está hidratada, apresenta-se com aspecto suave ao toque, macia e uniforme, já uma pele seca a sua perda da suavidade é notória, com aparência áspera, opaca e às vezes descamativa. Geralmente a pele seca está associada a menos produção de lipídeos secretados pela glândula sebácea e a pele hidratada tem uma maior produção destes lipídeos.

Os microrganismos da microbiota normal da pele podem contaminar cosméticos durante a aplicação e tornarem-se patogênicos diante de situações em que a barreira de proteção tem pequenas fissuras na epiderme ou quando os indivíduos se encontram imunocomprometidos (Silva, 2017).

Nos estudos analisados, esperava-se que os cosméticos não apresentassem uma contaminação significativa, devido ao Controle de Qualidade destes produtos, porém, como foi possível visualizar nos Resultados, todos os estudos obtiveram resultados aparentes em relação a contaminação, divergindo apenas nos gêneros dos microrganismos encontrados.

Segundo Marques e Moreira (2009) a contaminação microbiológica é um dos vários problemas encontrados na produção de cosméticos, sendo um dos principais agentes que podem impossibilitar a produção e comercialização de uma gama de produtos. Para a obtenção de um cosmético de boa qualidade microbiológica torna-se necessário não só a ausência de microrganismo patogênico, mas também a garantia que a carga microbiana não patogênica seja a menor possível e que as concentrações dos agentes estejam dentro das concentrações legalmente permitidas.

Um grande número de microrganismos com potencial patogênico pode estar presente nos produtos cosméticos, como vírus, bactérias e fungos, e, portanto, o ato de compartilhar tais produtos pode impactar em riscos à saúde do usuário (Mota, et al., 2017)

Accacio, almeida e Boni (2015) destacam que os microrganismos mais comuns encontrados em cosméticos contaminados, como rímel, lápis de olho e acessórios de estética são os Staphylococcus, das espécies aureus e epidermidis, os quais são classificados como cocos gram-positivos. As máscaras de cílios são expostas à contaminação através do usuário, desta forma a presença conservação pode ajudar a inibir o crescimento de microrganismos.

As reações mais temidas por maquiagens contaminadas são as infecções, principalmente as infecções da córnea por Pseudomonas aeruginosa, que podem anular permanentemente a acuidade visual. Estas infecções são mais comuns se o globo ocular for afetado pela máscara de cílios ou lápis de olho infectados. Além disso, os cosméticos que se aproximam da borda dos olhos podem acabar levando microrganismos para o globo ocular. Por esse meio de contato pode causar blefarite, que é 
uma inflamação na base dos cílios, ou hordéolo, popularmente conhecido como terçol. A maquiagem também pode passar quadros virais, como a conjuntivite, a qual também pode ser adquirida por bactérias (Accacio et al., 2015).

Os fungos também podem contaminar maquiagens e acessórios. As infecções fúngicas podem ocorrer como superficial subcutânea e sistêmica e são na sua maioria causadas por fungos filamentosos, dermatófitos e fungos leveduras pertencentes aos gêneros Candida incluindo, Malassezia e Cryptococcusy. (Benvenutti et al., 2016).

Segundo Martelli et al., (2005) e Fiorentino et al., (2008) o Controle de qualidade pode ser definido como o conjunto de operações (programação, coordenação e execução) que tem como objetivo verificar a conformidade das preparações com as especificações estabelecidas. É de grande importância avaliar pontos críticos de contaminação e estabelecer normas de controle, a fim de obter produtos de excelente qualidade, estabilidade e confiança.

Andrade et al. (2005) destaca que o objetivo imediato do controle de qualidade microbiológico de produtos não estéreis, nos quais admite-se a presença de carga microbiana limitada, é comprovar a ausência de microrganismos patogênicos e determinar o número de microrganismos viáveis, em função da utilização do produto. E ressalta que carga microbiana elevada pode comprometer a estabilidade do produto, consequentemente, pode haver perda da eficácia terapêutica, por degradação do princípio ativo ou por alteração de parâmetro físico fundamental para a sua atividade, como o pH. Além disso, alterações das propriedades físico-químicas também podem afetar a ação terapêutica comprometendo a biodisponibilidade do produto e a aceitação do mesmo pelo consumidor.

Neste estudo, os resultados das pesquisas analisadas apresentaram uma grande coerência em relação aos microrganismos encontrados, sendo possível perceber que em sua grande maioria foram encontrados bactérias do grupos Staphylococcus, sendo elas subdivididas em: aureus e epidermidis. As Staphylococcus aureus são bactérias regularmente encontradas em fossas nasais e pele de indivíduos salubres. Porém, podem causar desde infecções brandas como espinhas, celulites e furúnculos até infecções mais complexas, como pneumonia, meningite, endocardite, síndrome do choque tóxico, septicemia, entre outras (Santos et al., 2007). Já a epidermidis apesar de fazer parte da microbiota humana, S. epidermidis podem causar doenças como bacteremias/septicemias, endocardites, meningites, peritonites, endoftalmite, osteomielites, artrites, infecções do trato urinário, entre outras (Trabulsi \& Alterthum, 2008). Essas bactérias foram encontradas em 7 dos 8 estudos escolhidos.

Em contrapartida, em apenas 1 estudo foram encontradas Klebsiella sp, Kocuria Kristinae, Aspergillus niger, segundo Hassan et al. a espécie Kocuria Kristinae, uma bactéria geralmente não patogênica, amplamente distribuída na natureza e frequentemente encontrada na flora normal da pele e mucosa, infecções relacionadas a Kocuria Kristinae são incomuns em humanos saudáveis, entretanto foram relacionadas como causadores de infecções em pacientes imunocomprometidos com doenças subjacentes, estando, também, associadas com infecções do trato urinário, endocardite, peritonite e colecistite (Laks Hmikantha, et al.,2015). Outro gênero que também foi encontrado neste mesmo estudo foi, Klebsiella que de acordo Pereira Scl e Vanetti Mcd (2015), é constantemente estão associadas a infecções nosocomiais, representando alta morbimortalidade em pessoas, Segundo Hazen TH, et al. (2014), a Klebsiella pneumoniae é a espécie de maior patogenicidade pertencente a esse gênero e são frequentemente relacionadas a infecções do trato urinário, pneumonia, gastroenterite,meningite e septicemia.

No entanto, outro estudo com amostras apenas de batons, observou uma grande presença de Bacillus sp., Cladosporium sp., Aspergillus sp, além das baterias do grupo Staphylococcus, que nos mostra uma visão diferente em relação a outros estudos que também utilizaram o batom como amostra porém não encontraram contaminação por esses gêneros dando a entender que possivelmente ocorreu outro tipo de contaminação. Já no estudo realizado por Rodrigues, Luana Romão, et al. "Análise Microbiológica de Batons de Uso Compartilhado na Cidade de Juazeiro do Norte-CE." divergindo do estudo citado anteriormente aqui também foram utilizadas amostras de batom, porém houve um crescimento significativo de outros gêneros 
como: Escherichia coli; Enterococcus sp; Pseudomonas aeruginosa, o autor indicou nesses resultados que os sistemas conservantes utilizados nesses produtos não foram eficazes. Diferentemente deste estudo, esse trabalho teve presença maior de enterobactérias, o que pode estar relacionado com o manuseio e a falta de higienização desses batons.

Com isso podemos entender que esse estudo mostra que por serem produtos não estéreis os cosméticos podem ser contaminados de várias maneiras, inclusive os produtos de uso coletivo como provadores de lojas, onde várias pessoas utilizam os mesmos produtos em suas peles, lábios, olhos etc. Os artigos nos mostram que na maioria das analisados realizadas foram constatados a presença de bactérias do grupo Staphylococcus em 7 dos 8 estudos, sendo elas subdivididas em: aureus e epidermidis, o que representa um certo alerta pois tais bactérias podem trazer prejuízos para a saúde humana, que vão desde infecções simples até as mais complexas, além de todos os outros gêneros encontrados que em sua grande maioria também podem causar prejuízos não só a saúde da pele mais devido ao fato de que os cosméticos são produtos não estéreis.

\section{Considerações Finais}

A partir da análise dos resultados apresentados, observou-se que na maioria dos estudos analisados foram constatados nos cosméticos a presença de bactérias do grupo Staphylococcus, sendo elas subdivididas em: aureus e epidermidis. Tais bactérias podem trazer prejuízos para a saúde humana, que vão desde infecções simples até as mais complexas. Do ponto de vista microbiológico, os produtos cosméticos para maquiagem, por apresentarem composição complexa, servem como fontes de nutrientes para vários tipos de microrganismos, podendo sofrer contaminação em diversas etapas desde o seu desenvolvimento e produção até sua utilização.

Frente ao exposto, este estudo demonstra a importância do controle de qualidade de maquiagens e a eficiência dos conservantes devido ao alto risco de contaminação por microrganismos patogênicos oportunistas. Espera-se que a pesquisa possa contribuir para estudos futuros sobre o tema. A presente pesquisa teve por objetivo analisar estudos científicos que avaliaram a presença de microrganismos patogênicos em cosméticos, sendo realizada uma revisão sistemática da literatura a fim de reunir estudos semelhantes, publicados ou não, avaliando-os criticamente em sua metodologia e reunindo-os numa análise estatística, a metanálise.

\section{Referências}

Accacio, L. L., Almeida, C. R. D., \& Boni, S. M. (2015). Presença de Staphylococcus Aureus e Staphylococcus Epidermidis em máscaras de cílios utilizadas em salões de beleza na cidade de Sarandi-Pr.

Araújo, R. S. D., Pereira, C. R., Costa, C. M. D. S., Araújo, I. P., Mendes, C. L. Z., \& Gonçalves, G. S. (2018). Avaliação de contaminante microbiológicos em produtos cosméticos. Revista De Iniciação Científica Newton Paiva, Belo Horizonte, 35-39.

De Souza Benvenutti, A., Veiga, A., Rossa, L. S., \& Murakami, F. (2016). Avaliação Da Qualidade Microbiológica De Maquiagens De Uso Coletivo. Arquivos De Ciências Da Saúde Da Unipar, 20(3).

Chorilli, Marlus Et Al. (2009). Ensaios biológicos para avaliação de segurança de produtos cosméticos. Revista De Ciências Farmacêuticas Básica E Aplicada, P. 19-30.

Duarte, J. M. A., De Jesus Cortez, G., Dos Santos Silva, L., Pereira, L. D. R., \& Da Fonseca, P. F. S. (2020). Análises microbiológicas comparativas de pós compactos lacrados e em uso. Seminário transdisciplinar da saúde, (07).

Galembeck, F., \& Csordas, Y. (2011). Cosméticos: a química da beleza. Coordenação central de educação a distância.

Garbaccio, J. L., \& De Oliveira, A. C. (2018). Biossegurança em salões de beleza: avaliação da estrutura e dispositivos. Revista De Enfermagem Do CentroOeste Mineiro, 8 .

Tavares, R. S. (2021). Lactobacillus Spp. Como forma de controle biológico de fitobactérias do Tomateiro (Solanum Lycopersicum L.).

Lucas, R. (2004). Semiologia da pele. Semiologia veterinária: a arte do diagnóstico. Editora Roca, 641-676.

Moreira, M. F., \& ML, M. (2009). Análises microbiológicas de protetor solar manipulado nas farmácias magistrais do município de Ipatinga/MG. Rev Bras Farm, 90(2), 137-43. 
Research, Society and Development, v. 10, n. 16, e252101623885, 2021

(CC BY 4.0) | ISSN 2525-3409 | DOI: http://dx.doi.org/10.33448/rsd-v10i16.23885

Mota, V. A. M., Junior, J. A. O., \& Chiari-Andréo, B. G. (2017). O controle da contaminação microbiológica de produtos magistrais. Revista Brasileira Multidisciplinar, 20(1), 33-48

Macedo, C. H. C., Pierote, B. L. F., Pereira, K. A. B. N., Da Silva, K. M. R., Da Silva, K. M. R., Da Silva Sampaio, J. P., \& Junior, A. L. G. (2020). Análise microbiológica de provadores de maquiagens. Revista Eletrônica Acervo Saúde, 12(3), E2582-E2582.

Sartori, L. R., Lopes, N., \& Guaratini, T. (2010). A química no cuidado da pele. Sociedade Brasileira De Química.

Silva, J. C. P. A.; Camargo, B. (2017). Contaminação de maquiagens de uso coletivo por Staphylococcus Aureus e Staphylococcus Epidermidis. Anais Do Simpósio De Trabalho De Conclusão De Curso, V. 12, P. 451-456.

Simões, N. R. Q. (2015). Avaliação da qualidade microbiana de pós cosméticos.

De Aquino Souza, N., \& Sáber, M. L. (2019). Análise da presença de staphylococcus sp. Em creme labial de manteiga de cacau antes e após o uso. Revista Eletrônica Acervo Saúde/Electronic Journal Collection Health ISSN, 2178.

Nissen, L. P., Vieira, L. H., Bozza, L. F., da Veiga, L. T., Biscaia, B. F. L., Pereira, J. H., \& Furlan, L. H. P. (2012). Intervenções para tratamento da obesidade: revisão sistemática. Revista Brasileira de Medicina de Família e Comunidade, 7(24), 184-190.

De Souza, P. H. R., \& Oliveira, M. A. S. (2015). Indicadores de prescrição médica: uma revisão sistemática. Infarma-Ciências Farmacêuticas, $27(1), 5-13$.

Soares, A. H. R., Martins, A. J., Lopes, M. D. C. B., Britto, J. A. A. D., Oliveira, C. Q. D., \& Moreira, M. C. N. (2011). Qualidade de vida de crianças e adolescentes: uma revisão bibliográfica. Ciência \& Saúde Coletiva, 16, 3197-3206.

Marconi MA, Lakatos EM. Metodologia do trabalho científico: procedimentos básicos, pesquisa bibliográfica, projeto e relatório, publicações e trabalhos científicos. Atlas; 2008. 